107 Royal Netherlands Institute for Sea Research

This is a postprint of:

Martínez Martínez, J., Boere, A., Gilg, I., Lent, J.W.M. van, Witte, H., Bleijswijk, J.D.L. van \& Brussaard, C.P.D., (2015) New lipid envelope-containing dsDNA virus isolates infecting Micromonas pusilla reveal a separate phylogenetic group Aquatic Microbial Ecology, 74, 17-28

Published version: $\underline{\mathrm{dx} . \mathrm{doi} . \mathrm{org} / 10.3354 / \mathrm{ame} 01723}$

Link NIOZ Repository: $\underline{w w w} \cdot \mathbf{v l i z} \cdot$ be/nl/imis? module=ref\&refid=245848

[Article begins on next page]

The NIOZ Repository gives free access to the digital collection of the work of the Royal Netherlands Institute for Sea Research. This archive is managed according to the principles of the Open Access Movement, and the Open Archive Initiative. Each publication should be cited to its original source - please use the reference as presented.

When using parts of, or whole publications in your own work, permission from the author(s) or copyright holder(s) is always needed. 


\section{New lipid envelop-containing dsDNA virus isolates infecting Micromonas pusilla reveal a separate phylogenetic group.}

5 Joaquín Martínez Martínez ${ }^{1,4} *$, Arjan Boere ${ }^{1}$, Ilana Gilg ${ }^{4}$, Jan WM van Lent ${ }^{2}$, Harry J Witte $^{1}$, Judith DL van Bleijswijk ${ }^{1}$, Corina PD Brussaard ${ }^{1,3}$

${ }^{1}$ Department of Biological Oceanography, Royal Netherlands Institute for Sea

Research, PO Box 59, NL-1790 AB Den Burg, The Netherlands

10 2Laboratory of Virology, Department of Plant Sciences, Wageningen University,

Droevendaalsesteeg 1, 6708 PB, Wageningen, the Netherlands.

${ }^{3}$ Aquatic Microbiology, Institute for Biodiversity and Ecosystem Dynamics, University of Amsterdam, Amsterdam, The Netherlands

${ }^{4}$ Present address: Bigelow Laboratory for Ocean Sciences, 60 Bigelow Drive, East 15 Boothbay, $04544 \mathrm{ME}$, USA.

*Corresponding author: jmartinez@bigelow.org 


\section{Abstract}

Viral infection of phytoplankton has major implications for biochemical and energy cycles, community dynamics, and microbial evolution in the marine environment. The non-bloom forming picoplankter Micromonas pusilla, a significant component of the plankton community worldwide, is known to be susceptible to

25 infection by both dsDNA and dsRNA viruses. Logically, comprehensive knowledge of the ecology of $M$. pusilla requires a better understanding of the diversity and infection mechanisms of their viruses. Here, we investigated 19 new M. pusillaspecific viruses (MpVs) isolated from different locations and years. We performed partial characterization of those $\mathrm{MpVs}$ including structural characteristics, genome

30 size, phylogenetic analysis based on partial DNA polymerase gene sequences, host range, and stability at different temperatures and upon exposure to chloroform. Combined, these characteristics allowed classification of the MpVs into two groups. Exposure to chloroform led to loss of infectivity by all $\mathrm{MpVs}$ in one group, which suggests the presence of an outer lipid envelop. In addition, all except one of the members in that group formed a monophylogenetic clade that was distinct from all other $\mathrm{MpV}$ isolates. The distinctive characteristics of the two $\mathrm{MpV}$ groups suggest different infection strategies, which may have important implications for the ecology of both host and virus populations in the environment. Knowledge gained from our study adds value to the $\mathrm{MpV}$ isolates as a scientific resource as it will aid in 40 developing and testing in the laboratory new hypotheses about the ecological and biogeochemical implications of $M$. pusilla viral infection in the environment. 


\section{Keywords}

Micromonas pusilla; Virus diversity; Phycodnaviridae; NCLDV; Characterization; Lipids

\section{Introduction}

Viruses are the most abundant biological entities in marine environments (Bergh et al. 1989, Danovaro et al. 2001) and are major players in the microbial food web. Viruses facilitate the movement of nutrients from organisms to pools of dissolved and nonliving particulate organic matter, a process termed the viral shunt (Wilhelm \& Suttle 1999). The viral shunt affects microbial turnover rates and hence energy and material fluxes. Furthermore, viruses have a profound effect on microbial population dynamics and in shaping microbial evolution mainly through DNA or RNA transduction (Thingstad 2000, Brüssow et al. 2004, Martínez Martínez et al. 2006, Rohwer \& Vega-Thurber 2009). Viral infection constitutes a significant source of phytoplankton mortality in environmental aquatic communities and can even be responsible for the demise of large phytoplankton populations within a time scale of days (Bratbak et al. 1993, Brussaard et al. 1996, Evans et al. 2003, Baudoux et al. 2006, Martínez Martínez et al. 2012). Viruses have been isolated that infect many taxa of marine eukaryotic phytoplankton including Micromonas pusilla (Mayer \& Taylor 1979, Cottrell \& Suttle 1991, Brussaard et al. 2004) a member of the class Prasinophyceae, which is considered to be the most primitive in the green lineage from which all other green algae and land plant classes have risen (Sym \& Pienaar 1993). M. pusilla is a purely planktonic, naked, highly motile, non-blooming unicellular picoflagellate (1-3 $\mu \mathrm{m}$ in diameter) and is ubiquitous in coastal and oceanic marine waters throughout 
temperate and cold oceanic regions where it can occur as a prominent constituent of the picoplankton community (Manton \& Parke 1960, Zingone et al. 1999, Not et al. 2004, Šlapeta et al. 2006). Predicted climate change outcomes such as increased water column stratification and reduced nutrient concentrations in ocean surface waters can favor picoplankton growth (Schaum et al. 2013), and thus M. pusilla dynamics may be useful indicators of ecosystem change.

The $M$. pusilla virus originally isolated from seawater samples collected in the Strait of Georgia, British Columbia (Mayer \& Taylor 1979) was the first algal virus ever isolated. Many other dsDNA $M$. pusilla viruses have subsequently been isolated from numerous distant geographic locations (Waters \& Chan 1982, Cottrell \& Suttle 1991, Sahlsten 1998, Zingone et al. 2006, Bellec et al. 2009). Additionally, a dsRNA MpV M. pusilla virus (Mimovirus MpRV) member of the family Reoviridae was isolated from a Norwegian coastal seawater sample using $M$. pusilla strain LAC38 (Brussaard et al. 2004). All M. pusilla viruses isolated so far are icosahedral and large in particle size (90-95 nm, MpRV; 100-135 nm, dsDNA M. pusilla viruses). The dsDNA M. pusilla viruses belong to the algal virus family Phycodnaviridae, which is part of a group of viruses known as nucleocytoplasmic large dsDNA viruses (NCLDVs) that replicate in the cytoplasm and in some cases partly in the nucleus of their eukaryotic host cells (Iyer et al. 2001). Research stemming from independent studies of $M$. pusilla-specific viruses has revealed significant genetic diversity within dsDNA M. pusilla viruses (Cottrell \& Suttle 1991, 1995, Bellec et al. 2014), some knowledge of their infection strategy and effect on host physiology (Mayer \& Taylor 1979, Waters \& Chan 1982), variation in strain specificity (Sahlsten 1998, Brussaard et al. 2004), and evidence for significant cospeciation between these viruses and their 90 hosts in addition to host switches (Bellec et al. 2014). Furthermore, investigations of 
their dynamics in the environment have shown seasonal and spatial variation in abundance (Cottrell \& Suttle 1991, Sahlsten 1998, Zingone et al. 1999) and have indicated the importance of viruses as mortality agents of $M$. pusilla (Evans et al. 2003). Better understanding of the ecology of $M$. pusilla under current and future oceanic conditions is directly linked to better insight into the diversity and infection mechanisms of specific viruses as drivers of the dynamics and evolution of M. pusilla. In the era of "cultivation-independent omic" methods, having well characterized model virus-host systems in culture is still essential to investigate the environmental parameters that affect viral replication success and specificity as well as to aid in understanding the mechanisms of virus-host interactions and their ecological and biogeochemical consequences through hypothesis driven experimental manipulation. In this study, we report the partial characterization including host range, genome sizing, phylogenetic reconstruction based on the DNA polymerase B gene, heat-inactivation experiments, and effect of exposure to chloroform for nineteen new dsDNA M. pusilla virus isolates from several locations throughout the North Sea and Dutch coastal waters, the Mediterranean Sea and the English Channel. Our findings add to the accumulating scientific knowledge on this group of interesting viruses and reveal new aspects of $M$. pusilla virus diversity with potentially significant implications for the ecology of the M. pusilla-virus system.

\section{Materials and methods}

\section{Algal cultures}

Single strain cultures of the Prasinophyceae M. pusilla (Butcher) Manton and Parke, were obtained from the Roscoff Culture Collection (RCC strains - clades specified in Table 1), the National Center for Marine Algae and Microbiota at 
115 Bigelow Laboratory for Ocean Sciences (strain CCMP 1545 - clade C) and the Culture Collection at the Marine Research Center of Göteborg University (strain LAC 38 - clade A) (Table 1). The algal cultures were maintained at $15^{\circ} \mathrm{C}$ and kept at mid-

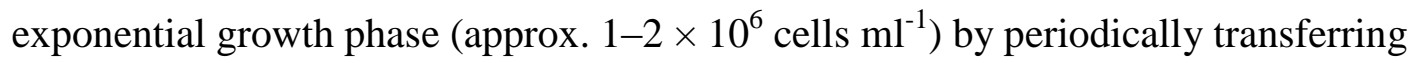
5-10\% (v/v) culture in a fresh 1:1 mixture of f/2-Si medium (Guillard 1975) and enriched artificial seawater (ESAW) (Cottrell \& Suttle 1991). Light (50-100 $\mu \mathrm{mol}$ photons $\mathrm{m}^{-2} \mathrm{~s}^{-1}$ ) was supplied by fluorescence tubes under a light-dark cycle of 16:8 hours. Cell abundances were calculated by flow cytometry (FCM) on fresh samples as described by Marie et al. (Marie et al. 1999) using a FACScalibur flow cytometer (Becton Dickinson, Franklin Lakes, NJ), equipped with an air-cooled laser providing

$12515 \mathrm{~mW}$ at $488 \mathrm{~nm}$ and with standard filter set-up. Trigger was set on red chlorophyll autofluorescence.

\section{Virus isolation and propagation}

Lytic viruses infectious to $M$. pusilla were isolated during spring and summer of different years from seawater samples originating from several geographical

130 locations in the North Sea, the Dutch coastal waters, the English Channel and the Mediterranean Sea (Table 2). Isolation was conducted by adding filtered (GF/F filters, Whatman, GE Healthcare Europe GbmH, Germany) seawater to exponentially growing M. pusilla strains CCMP1545 and LAC38 cultures (10\% v/v) in clear borosilicate tubes. The cultures were incubated for up to 14 days under the light and

135 temperature conditions described above, and were inspected daily for lysis. Lysis was determined by colour comparison to non-inoculated control cultures. Lysed cultures were filtered through $0.2 \mu \mathrm{m}$ pore size polyestersulfone (PES) filters (Minisart ${ }^{\circledR}$ High-flow, Sartorius, Rotterdam, the Netherlands) and used to reinfect fresh exponentially growing algal cultures. $M$. pusilla virus isolates were made clonal 
140 (henceforth referred to as MpVs) by end-point dilution as described by Brussaard et al. (2004). Virus strain MpVSP1 was provided by Dr. C. Suttle, UBC, Canada, and originated from waters off Southern California (Cottrell \& Suttle 1991).

Virus production was quantified using flow cytometry. For FCM analysis, samples were fixed with glutaraldehyde (0.5\% final concentration, EM grade, Sigma-

145 Aldrich) during $30 \mathrm{~min}$ at $4{ }^{\circ} \mathrm{C}$ followed by freezing in liquid nitrogen and storage at $80{ }^{\circ} \mathrm{C}$ until analysis. Thawed samples were diluted in TE 10:1 buffer (10 mM Trisbase, $1 \mathrm{mM}$ EDTA, $\mathrm{pH}$ 8.0) and stained with the nucleic acid-specific dye SYBR Green I (Life Technologies, Grand Island, NY) as described by Brussaard (2004). The identity of the MpV population discriminated by FCM after infection and

150 subsequent lysis was verified by comparison to $\mathrm{MpV}$-free cultures at mid-exponential and stationary growth phase, which showed no virus-like particles in the " $\mathrm{MpV}$ region" (Supplementary Figure S1).

\section{Transmission electron microscopy (TEM)}

Aliquots of virus lysates ( $20 \mathrm{ml}$, filtered through $0.2 \mu \mathrm{m}$-pore size filters) were 155 concentrated by ultracentrifugation $\left(142,000 \times \mathrm{g}\right.$ for $2 \mathrm{~h}$ at $8^{\circ} \mathrm{C}$, in a Centrikon T-1080 Ultracentrifuge, with a TFF55.38 rotor, Kontron Instruments). The viral pellets were resuspended in $100 \mu \mathrm{l}$ of TE 10:1 buffer. The concentrated suspensions were fixed with formaldehyde and centrifuged onto electron microscope nickel grids with carbon-coated formvar film in a Beckmann airfuge for $20 \mathrm{~min}$ at 30 psi. The grids were negatively stained with $2 \%$ uranyl acetate and viewed in a Philips CM12 transmission electron microscope.

Additionally, we used TEM to screen thin sections from M. pusilla cells infected (4-12 h after infection) with two randomly selected isolates for each host to confirm that the virus particles observed by FCM and TEM in lysate samples were 
indeed infectious to $M$. pusilla. Infected algal cells were fixed by addition of glutaraldehyde to a final concentration of $0.1 \%$ and after $30 \mathrm{~min}$, cells were pelleted by centrifugation at 3,200 $\times \mathrm{g}$ for $5 \mathrm{~min}$. Cells were resuspended in $2 \%$ gelatin, pelleted again and the pellet was cut in small cubes of approximately $0.5 \mathrm{~mm}$. These samples were further fixed for $2 \mathrm{~h}$ in $2 \%$ glutaraldehyde/3\% paraformaldehyde in phosphate/citrate buffer $\left(0.1 \mathrm{M} \mathrm{Na}_{2} \mathrm{HPO}_{4} \cdot 2 \mathrm{H}_{2} \mathrm{O}\right.$ and $9.7 \mathrm{mM}$ citric acid , $\left.\mathrm{pH} 7.2\right)$ containing $2.5 \mathrm{mM} \mathrm{CaCl}_{2}$, washed $6 \times 10 \mathrm{~min}$ in phosphate/citrate buffer and fixed with $1 \%$ osmium tetroxide in phosphate/citrate buffer for $1 \mathrm{~h}$. Samples were washed, dehydrated in a graded series of ethanol (50 to 100\%) and infiltrated with LR White (London Resin company) Samples were transferred to gelatin capsules filled with resin and polymerized for $48 \mathrm{~h}$ at $55^{\circ} \mathrm{C}$. Sections were cut using a Leica Ultracut $\mathrm{S}$ ultramicrotome and stained with $2 \%$ uranyl acetate and lead citrate (Reynolds) before examination in a Philips CM12 transmission electron microscope. Average capsid sizes were determined by measuring 10 virus particles for each isolate.

\section{Genome size}

Freshly produced $\mathrm{MpV}$ lysates were partially purified by removing cell debris and bacteria by centrifugation $\left(7,500 \times \mathrm{g}\right.$ for $30 \mathrm{~min}$ at $4^{\circ} \mathrm{C}$, using a fixed-angle rotor F-34-6-38 in a 5810R centrifuge, Eppendorf). The genome size of the individual MpV isolates was determined by Pulse Field Gel Electrophoresis (PFGE) as described in Baudoux and Brussaard (2005). Briefly, the clarified supernatant was decanted and viral particles were pelleted by ultracentrifugation $\left(142,000 \times \mathrm{g}\right.$ for $2 \mathrm{~h}$ at $8^{\circ} \mathrm{C}$, in a Centrikon T-1080 Ultracentrifuge, with a TFF55.38 rotor, Kontron Instruments) and resuspended in $150 \mu \mathrm{l} \mathrm{SM}$ buffer $\left(0.1 \mathrm{M} \mathrm{NaCl}, 8 \mathrm{mM} \mathrm{MgSO}_{4} \cdot 7 \mathrm{H}_{2} \mathrm{O}, 50 \mathrm{mM}\right.$ Tris$\mathrm{HCl}, 0.0005 \%$ (w/v) glycerine). Plugs (at least 3 per virus isolate) were prepared by mixing equal volumes of virus concentrate and molten $1.5 \%(\mathrm{w} / \mathrm{v})$ InCert agarose 
190 (Cambrex Bioscience, Rockland, ME, USA) in plastic molds. Once hardened, the plugs were incubated overnight at $30^{\circ} \mathrm{C}$ in $800 \mu$ of lysis buffer $(250 \mathrm{mM}$ EDTA, $1 \%$ SDS (v/v), $1 \mathrm{mg} \mathrm{ml}^{-1}$ proteinase K, Sigma-Aldrich, Zwijndrecht, The Netherlands). After decanting, the digestion buffer the plugs were washed in TE 10:1 buffer (10 $\mathrm{mM}$ Tris-Base, $1 \mathrm{mM}$ EDTA, $\mathrm{pH}$ 8.0). The plugs were stored at $4^{\circ} \mathrm{C}$ in TE 20:50 (20 mM Tris, 50 mM EDTA, pH 8.0) until analysis. Plugs were loaded alongside DNA Lambda ladder plugs (Bio-Rad, Richmond, CA) onto 1\% SeaKem GTG agarose gels (Cambrex Bioscience, Rockland, ME USA) prepared in $1 \times$ TBE gel buffer $(90 \mathrm{mM}$ Tris-Borate and $1 \mathrm{mM}$ EDTA, $\mathrm{pH}$ 8.0). Samples were electrophoresed in a Bio-Rad CHEF DR-II Cell unit filled with 0.5x TBE buffer (45 mM Tris-Borate and $0.5 \mathrm{mM}$

200 EDTA, pH 8.0), at $6 \mathrm{~V} / \mathrm{cm}$ with pulse ramps of 20 to $45 \mathrm{~s}$ at $14^{\circ} \mathrm{C}$ for $22 \mathrm{~h}$. Gels were subsequently stained for at least $1 \mathrm{~h}$ with SYBR Green I $\left(1 \times 10^{4}\right.$ of commercial solution, Molecular Probes, Eugene, OR) and visualized in a FluorS imager (Bio-Rad Instrument). Genome sizes were estimated based on the migration of each individual genomic DNA band compared to a molecular size marker (note that this method

205 offers only approximate size values and complete genome sequencing is required for accurate genome sizing).

\section{Viral DNA purification}

Fresh MpV lysates $(25 \mathrm{ml})$ were centrifuged at $10,000 \times \mathrm{g}$ for 30 minutes at $4^{\circ} \mathrm{C}$ to remove most bacteria and cellular debris. The clarified lysate was incubated at $4^{\circ} \mathrm{C}$ overnight with $\mathrm{NaCl}$ (2 M final concentration) and PEG6000 (final concentration 10 wt\%) (CalBiochem, San Diego, CA, USA). The viruses were subsequently pelleted from the supernatant by centrifugation at $9,000 \times \mathrm{g}$ for 25 minutes at $4^{\circ} \mathrm{C}$, the supernatant was decanted and the pellet was air-dried for $\sim 10$ minutes. DNA was extracted by adding $500 \mu \mathrm{l}$ of prewarmed lysis buffer $(0.5 \%$ SDS, $20 \mu \mathrm{g} / \mathrm{ml}$ 
215 proteinase $\mathrm{K}$ ) to the pellet, and incubating at $55^{\circ} \mathrm{C}$ for 30 minutes. Then $80 \mu \mathrm{l}$ of $5 \mathrm{M}$ $\mathrm{NaCl}$ and $100 \mu \mathrm{CTAB}-$ buffer $(10 \%$ hexadecyltrimethyl ammonium bromide $[\mathrm{CTAB}]$ in $0.7 \mathrm{M} \mathrm{NaCl}$ ) were added and the mixture was incubated again at $65^{\circ} \mathrm{C}$ for $15 \mathrm{~m}$, after which $500 \mu \mathrm{l}$ of Chloroform : Isoamylalcohol (24:1) was added and mixed well. The samples were then centrifuged at $20,000 \times \mathrm{g}$ for 5 minutes and aqueous

220 phase containing the DNA was transferred to a new tube. Finally, DNA was precipitated using a standard isopranol precipitation method and resuspended in $50 \mu 1$ of TRIS (50mM, pH8). DNA yield and quality were checked using a NanoDrop® ND-1000 (Thermo Scientific, Wilmington, DE, USA).

\section{PCR amplification and sequencing of viral DNA polymerase B gene fragments}

Virus DNA templates were diluted 5,000-fold in molecular-grade water and DNA polymerase fragments were amplified from each template using previously described PCR and thermocycling conditions with AVS1-AVS2 primers (Chen \& Suttle $1995 \mathrm{a}, \mathrm{b})$ modified by adding a M13 tag (5'-CAC GAC GTT GTA AAA CGA C [primer]-3') to both primers. Two separate PCRs were run, one with the AVS1-

230 M13 and AVS2, and one with the AVS1 and AVS2-M13 primers. Finally, the PCR amplicons were cleaned up using Genscript PCR Clean-up kit (Genscript Inc., Piscataway Township, NJ, USA) according to the manufacturer's recommendations, prior to BigDye cycle sequencing on an ABI prism 310 Genetic analyser at the Royal Netherlands Institute for Sea Research. M. pusilla virus DNA polymerase sequences generated in this study were deposited into GenBank (accession numbers in Table 2).

DNA sequences from our MpV isolates were aligned with an additional $35 \mathrm{M}$. pusilla virus DNA polymerase B partial sequences available through GenBank and previously published (Chen and Suttle (1996) Bellec et al. (2014)). Five Ostreococcus virus and two Bathycoccus virus DNA polymerase B partial sequences (Bellec et al. 
240 2014) were included as an outgroup. The sequences were initially aligned using the ClustalX algorithm (Larkin et al., 2007) within MEGA version 6 (Tamura et al., 2013). The alignment was manually refined and a sequence mask was applied to retain regions of unambiguous alignment; only those positions were included in subsequent phylogenetic analyses. The alignment was subjected to a Bayesian

245 Inference (BI, generally more suitable for phylogenetic reconstruction of highly similar sequences) using MrBayes, version 3.2.1 (Ronquist et al. 2012). We used the GTR model of substitution (Lanave et al. 1984; Rodriguez et al. 1990, Tavare 1986), considering invariants and a gamma-shaped distribution of the rates of substitution among sites. We used 4 chains of 1,000,000 generations and trees were sampled every

250100 generations using a Markoff Chain Monte Carlo (MCMC) analysis. Chain parameters appeared to be stationary after one hundred thousand sampled trees; the first 200,000 trees (20\%) were discarded as burn-in for the tree topology and posterior probability. The consensus tree was viewed and edited in MEGA version 6 (Tamura et al., 2013).

\section{Host range}

Susceptibility of $17 M$. pusilla strains, originated from different geographical locations (Table 1), to the $20 \mathrm{MpV}$ isolates was determined using fresh cultures and virus lysates. Briefly, each $\mathrm{MpV}$ isolate was added to exponentially growing cultures of each M. pusilla strain (10\% v/v, in triplicate). The inoculated cultures were gently 260 mixed daily to encourage virus adsorption and prevent host cells sedimentation. Host growth for each M. pusilla-MpV combination was monitored daily over a 14 day period. Lysis was determined by colour comparison to non-inoculated control cultures and virus production was verified by FCM. FCM analysis of non-infected controls proved the absence of a MpV-like group in these cultures. Cultures that had not lysed 
26514 days after the addition of an $\mathrm{MpV}$ innoculum were considered resistant to that virus strain.

In addition, a strain of the prasisinophyte Ostreococcus tauri RCC475 (obtained from the Roscoff Culture Collection) was included in the study to test if any of the $\mathrm{MpV}$ isolates was able to infect a different, but closely related, phytoplankton 270 species.

\section{Thermal stability and sensitivity to chloroform}

To determine the ability of the viral isolates to remain infectious after exposure to freezing temperatures, duplicate $0.5 \mathrm{ml} 0.2 \mu \mathrm{m}$-filtered aliquots of each virus lysate were stored (without addition of any cryoprotectant) at $-196^{\circ} \mathrm{C},-80^{\circ} \mathrm{C}$, and $-20^{\circ} \mathrm{C}$ for $24 \mathrm{~h}$. The aliquots were thawed at room temperature immediately prior to their addition to $5 \mathrm{ml}$ of exponentially growing host cultures (either $M$. pusilla strain CCMP 1545 or LAC38 used for original isolation) in borosilicate tubes. To determine viral stability at higher temperatures $\left(4^{\circ} \mathrm{C}, 15-40^{\circ} \mathrm{C}\right.$ in $5^{\circ} \mathrm{C}$ increments, $50^{\circ} \mathrm{C}$ and $60^{\circ} \mathrm{C}$ ), duplicate $0.5 \mathrm{ml}$ aliquots of each virus lysate were incubated at the specified temperatures for $10 \mathrm{~min}$ in a waterbath, followed by $5 \mathrm{~min}$ cooling on ice prior to addition to $5 \mathrm{ml}$ of the appropriate host culture. Duplicate virus-free cultures of both host strains served as negative controls. Inoculated and virus-free cultures were incubated under the normal culturing conditions described above and monitored daily for lysis over a 14-day period.

$\mathrm{MpV}$ lysate infectivity was also tested following 10 min incubation with $10 \%$ and $50 \%(\mathrm{v} / \mathrm{v})$ chloroform. The chloroform was separated from solution by centrifugation at $4,000 \times \mathrm{g}$ for $5 \mathrm{~min}$. The aqueous phases containing the viruses were transferred to clean tubes. These tubes were left with lids open at $4^{\circ} \mathrm{C}$ overnight to allow for evaporation of any remaining chloroform. Exponentially growing cultures 
290 (specific M. pusilla strain used for isolation) were inoculated with the treated viruses $(10 \% \mathrm{v} / \mathrm{v})$. The degree of infectivity was determined by end-point dilution with three replicates and twelve 10-fold dilution levels for each virus strain. Host samples that received the addition of $10 \% \mathrm{v} / \mathrm{v}$ of fresh culture medium or untreated $\mathrm{MpVs}$ served as controls. The experiment was performed using 96-well plates (approximately 200

$295 \mu \mathrm{l}$ volume per well) and borosilicate tubes (in $5 \mathrm{ml}$ volume assays) to rule out possible container or volume effects. Viral production in the last dilution that caused lysis was confirmed by FCM.

\section{Results}

\section{Ultrastructure analysis} TEM of thin sections of M. pusilla cells (strains CCMP1545 and LAC38, used for original $\mathrm{MpV}$ isolations (Table 2)) from cultures inoculated with viruses (4-12 hours post-infection) revealed degradation of nuclear material and the accumulation of virus particles in the cytoplasm, which was not present in non-inoculated cultures (Figure 1A-D). TEM analysis of lysed cultures revealed free virus particles uniform in 305 shape, size, and staining intensity that were comparable to those in the thin section photographs. Viruses isolated using either M. pusilla strain (MpVs) were tailless, with icosahedral symmetry as suggested by their hexagonal outline, and approximately $125 \pm 6 \mathrm{~nm}$ in diameter. The virus particles showed a thick outer layer surrounding an electron-dense inner core (Figure 1E).

\section{Genome size and type}

PFGE analysis revealed MpV genomes around $200 \mathrm{~Kb}$ (Table 2; Figure S2). The MpVs isolated using M. pusilla strain CCMP1545 (CCMP1545-MpV isolates hereafter) had smaller genomes, on average $191 \pm 4 \mathrm{~Kb}$, compared to isolates 
obtained using M. pusilla strain LAC38 (LAC38-MpV isolates hereafter), which were, on average, $206 \pm 6 \mathrm{~Kb}$. Since our cultures were not axenic, bands smaller than $48.5 \mathrm{~Kb}$ seen in some of the samples likely correspond to phages with small capsid and genome sizes present in the lysate.

Nucleic acid extraction and direct PCR amplification of the DNA polymerase B gene (considered a good phylogenetic marker for most members of the NCLDV group (Chen \& Suttle 1996, Yutin et al. 2009) confirmed that all virus isolates in this study contained dsDNA genomes (see below).

\section{Phylogeny}

Partial sequences of the DNA polymerase B gene amplified using previously designed AVS1-AVS2 primers (Chen \& Suttle 1995a, b) are highly conserved at the

325 nucleotide level among all our MpV isolates. Indeed, several of the newly isolated MpVs have nearly identical partial DNA polymerase B gene sequences. Nonetheless, our Bayesian inference showed strong support $(\mathrm{BI}$ posterior probability $=1)$ for two major clades. One, which contained all the new LAC38-MpV isolates except MpV38T and appeared to be monophyletic, and a second clade that contained all

330 remaining $\mathrm{MpV}$, OtV, and OlV sequences from this and other studies. However, the phylogenetic relationships in the second clade were poorly resolved (BI posterior probability $=0.58$ ). Based on the partial DNA polymerase B gene sequence, MpV38T appears phylogenetically closer to a number of MpVs from the English Channel (MicAV27, MicAV28, MicAV31, MicAV32, MicAV34) (Bellec et al. 2014) that

335 were isolated using a M. pusilla host that belonged to genetic clade A, like host strain LAC38 used for MpV38T isolation. Two of our CCMP1545-MpVs (MpV41T and MpV05T) were monophyletic to eight $M$. pusila viruses isolated by Cottrell and Suttle from a variety of geographical locations $(1991,1995)$ (grey labels, Figure 2) and to a 
subset of MpVs isolated in 2009 (Bellec et al. 2014) from English Channel waters, using clade C M. pusilla hosts, (MicCV21, MicCV22, MicCV23, MicCV28, MicCV36). Another smaller clade revealed that two other 1545-MpVs (MpV40T and MpV02T) were highly similar to MicC497V2. The remainder of our 1545-MpV isolates showed no clear affiliation with any previously-isolated virus. MpV40T and MpV41T were isolated from a single seawater sample collected in 2006 from the exact same location from where the MicC-viruses originated.

\section{Host range}

The M. pusilla strains included in this study showed variable susceptibility to infection, but none was resistant to all $\mathrm{MpV}$ isolates (Table 1). In contrast, the closely related prasinophyte Ostreococcus tauri strain RCC475 was resistant to infection by 350 all of the $20 \mathrm{MpVs}$ tested (data not shown). Multiple MpV isolates were capable of infecting the same host strains, yet their specificity was highly variable and ranged from MpVs capable of infecting as many as 16 of the $17 \mathrm{M}$. pusilla strains tested (e.g. MpV40T or MpV12T) to as few as 4 M. pusilla strains (Mediterranean isolates, MpV38T and MpV39T). Other than a reduced host range for the Mediterranean

355 isolates, no clear pattern in host susceptibility or virus infectivity was observed based on the geographical origin and time of isolation of either the host strains or the viruses. However, it is noteworthy that none of the CCMP1545-MpV isolates was able to infect M. pusilla strain LAC38 and vice versa (Table 1).

\section{Thermal stability and sensitivity to chloroform}

All of our $\mathrm{MpV}$ isolates remained infectious after freezing at $-20^{\circ} \mathrm{C},-80^{\circ} \mathrm{C}$ and $-196^{\circ} \mathrm{C}$ for 24 hours, and slow thawing at room temperature. However, LAC $38-\mathrm{MpV}$ isolates were more sensitive to high temperatures and lost infectivity following 
exposure to temperatures above $35^{\circ} \mathrm{C}$, while heat inactivation of CCMP1545-MpVs only occurred above $40^{\circ} \mathrm{C}$ (Table 3 ).

Treatment of the $\mathrm{MpV}$ isolates with either $10 \%$ or $50 \%$ chloroform resulted in complete loss of infectivity of all LAC38-MpV isolates, while none of the CCMP1545-MpV isolates lost infectivity (Table 3).

\section{Discussion}

All MpV isolates described here appeared to be assembled in the cytoplasm of the host and showed similar hexagonal morphology and particle diameter $(125 \pm 6 \mathrm{~nm})$. These characteristics are comparable to those of earlier published M. pusilla viruses (Mayer \& Taylor 1979, Cottrell \& Suttle 1991, Zingone et al. 2006). However, we were able to separate the new MpVs into two distinct groups based on patterns in: average genome size (larger genome size for LAC38-

375 MpVs isolates); susceptibility to viral infection of $M$. pusilla strains CCMP1545 and LAC38 (viruses that lysed one of this host strains could not lyse the other host strain and vice versa); sensitivity to different temperatures treatments (LAC38-MpV isolates more sensitive to high temperature exposure); and loss of infectivity following exposure to chloroform only by LAC38-MpV isolates. The same two virus groups could be resolved based on the phylogeny of their partial DNA polymerase B gene sequences, with the exception of MpV38T that was phylogenetically apart from the rest of LAC38-MpVs isolates. Overall, the phylogenetic grouping depending on the host strain and clade is consistent with that reported by Bellec et al. (2014). Some of our MpV isolates for M. pusilla strain CCMP1545 (clade C) are phylogenetically

385 close to six dsDNA M. pusilla viruses isolated from the English Channel (Bellec et al. 2014) and eight dsDNA M. pusilla viruses isolated from other distant geographical 
locations (Cottrell \& Suttle 1991, Chen \& Suttle 1996), one of which, MpVSP1, was included for comparison in our characterization study. The six English Channel $M$. pusilla viruses were isolated using M. pusilla strain RCC834 and the other eight $M$. 390 pusilla viruses were isolated and propagated using M. pusilla strain Plymouth27 (obtained from the algae culture collection at the University of Texas at Austin). Interestingly, $M$. pusilla strain Plymouth27 was the initial isolate from which strains RCC834 (Roscoff Culture Collection, Station Biologique Roscoff) and CCMP1545 (National Center for Marine Algae and Microbiota, Bigelow Laboratory) originated 395 (information obtained from culture collection sites). Furthermore, M. pusilla strain RCC834 was also included in our host range analysis but it showed different susceptibility to our MpV strains than CCMP1545. Indeed, RCC834 was susceptible to infection by eight of the twelve LAC38-MpVs. Changes in susceptibility to viral infection by two distinct host cultures originating from a common isolate have also 400 been reported for the phytoplankton species Emiliania huxleyi (Allen et al. 2007). It is likely that susceptibility differences observed for the two M. pusilla strains with a common origin, as for E. huxleyi, are due to changes in the host, adaptive or not, induced by slight changes in culture conditions under which the algae is maintained for long periods of time (Lakeman et al. 2009). The idea of changes in the host that can affect host range is also supported by the results from a recent study of genomic data that suggests slower evolutionary divergence of prasinoviruses than that of their hosts (Moreau et al. 2010).

MpVs belonging to the two groups described here coexist in the environment as several strains were isolated from the same water sample (e.g. MpV02T and -14T; MpV40T, -41T,-42T and -43T). However, we do not have data about the relative abundance and dynamics of members of both $\mathrm{MpV}$ groups that co-occur in the 
environment. Previous studies have investigated seasonal abundance and dynamics of M. pusilla and their viruses in geographically distant locations throughout coastal waters of the Pacific and Atlantic Oceans (Cottrell \& Suttle 1991), Scandinavian

415 waters (Sahlsten 1998) and the Mediterranean Sea (Zingone et al. 1999). All three studies reported the presence of dsDNA $M$. pusilla viruses at all times of the year, yet they varied among locations and temporally at the same location. In particular, Sahlsten (1998) investigated the abundance of M. pusilla viruses infectious to different M. pusilla host strains including strains LAC38, CCMP1545, and CCMP491

420 (a reclone of CCMP1545), and found that viruses infectious to M. pusilla strain LAC38 were numerically dominant at all time points. Host range analysis in that study is in accordance with our findings since $\mathrm{MpV}$ isolates infectious to M. pusilla strain LAC38 appear innocuous to strains CCMP1545 and CCMP491, and vice versa, under the specific culture and environmental conditions set during these studies. What 425 determines such specificity remains unanswered, especially given the fact that isolates obtained with M. pusilla strain LAC38 (clade A) can infect other clade C hosts and CCMP1545-MpVs can lyse clade A hosts other than LAC38. Further genomic and phenotypic characterization of both $M$. pusilla strains might aid in figuring out this conundrum. Unfortunately, no other parameters in Sahlsten's paper are comparable to 430 those in our study to allow us to place their $M$. pusilla virus isolates into either group as defined here.

Combined, the distinct effect of chloroform exposure and maintenance of infectivity at high temperature exposures differed between the $\mathrm{MpV}$ groups in this study, suggesting different infection efficiencies under various environmental 435 conditions and even possibly different propagation strategies. To our knowledge, this is the first study that reports the distinction between dsDNA M. pusilla viruses either 
susceptible or resistant to chloroform exposure. Maintenance of infectivity after exposure to chloroform by all of the members in the CCMP1545-MpVs group suggests that they lack a lipid membrane surrounding their capsids, i.e. they are nonenveloped viruses. The opposite argument is the case for LAC38-MpVs. To date, our understanding of the mechanisms of infection in prasinoviruses (dsDNA M. pusilla viruses) is limited. In the initial report of M. pusilla viruses isolation, Mayer and Taylor (1979) showed an infection mechanism similar to what is known for nonenveloped NCLDV members of the genera Chlorovirus and Phaeovirus (van Etten et 445 al. 2002, Wilson \& Allen 2009). Briefly, virus adhesion to the host cell surface is followed by fusion of a viral inner-membrane to the host membrane, allowing entry of the virus genome into the host, and leaving an empty extracellular capsid. Progeny particles form in the cytoplasm of the host and are released through localized rupture of the host's cell membrane. This infection mechanism is consistent with more recent observations on two M. pusilla virus isolates from Mediterranean waters (Zingone et al. 2006). Our TEM analysis did not provide information regarding the entry mechanisms of $\mathrm{MpVs}$ in this study, but shows $\mathrm{MpV}$ acummulation in the cytoplasm and rupture of the host's cell membrane. Yet, variations of infection strategies exist among members of the NCLDV group in particular regarding viral entry to and exit

455 from the host cell (Iyer et al. 2001, Law et al. 2006, Mackinder et al. 2009, Mutsafi et al. 2013). Such differences occur even within NCLDV families. For example the double membrane enveloped vaccinia viruses (family Poxviridae, animal viruses) can occur in three infectious forms with different structures, abundance and roles (Smith et al. 2002). The vaccinia viruses display a non-fusogenic outer membrane dissolution 460 allowing the inner envelope to fuse with the host's plasma membrane and releasing an intact virion core into the host's cytoplasm (Law et al. 2006, Doceul et al. 2010). E. 
huxleyi-virus EhV-86, another member of the NCLDV group, has a different infection mechanism than that described for other algal viruses (Chloroviruses, Phaeoviruses and Prasinoviruses). EhV-86's entry and exit strategies are more similar to those of animal NCLDVs. EhV-86 has a lipid membrane-enveloped capsid and although it is still not clear whether it enters its host via an endocytotic or an envelope fusion mechanism, an intact viral nucleoprotein core with its capsid reaches the host's cytoplasm. EhV-86 progeny is released via a budding mechanism during which the virions become again enveloped with host's plasma membrane (Mackinder et al. 2009). Based on our results, it is tempting to hypothesize that MpVs infectious to $M$. pusilla strain CCMP1545, which retained infectivity after treatment with chloroform, might be non-enveloped and follow an infection mechanism as previously described for other dsDNA M. pusilla virus isolates. On the contrary, the chloroform-sensitive viruses that infect $M$. pusilla strain LAC38 might carry lipid membranes around their 475 capsids and have entry and exit strategies similar to the ones described for EhV-86.

Furthermore, the loss of infectivity at temperatures above $35^{\circ} \mathrm{C}$ by viruses that infect $M$. pusilla strain LAC38, compared to infectivity maintenance up to $40^{\circ} \mathrm{C}$ by MpVs specific to M. pusilla strain CCMP1545, is in agreement with literature since the 1950s that indicates that non-enveloped viruses are usually more heat-resistant than viruses with a lipid bilayer envelope (Nims \& Plavsic 2013). The different sensitivity of MpVs with and without lipid envelopes to heat suggests variable ecological niche adaptation between both groups. Although it is unlikely that viruses get exposed to such high temperatures in the environment, the result may indicate differential ability among both $\mathrm{MpV}$ groups to handle longer term exposure to high temperatures, hence allowing niche differentiation and variable propagation success 
throughout changing environmental conditions, e.g. one $\mathrm{MpV}$ group could be more successful during warmer seasons and the other in colder seasons.

Finally, it is worth noting that the genomes of all the MpVs infectious to $M$. pusilla CCMP1545 are less than $200 \mathrm{~Kb}$ in size (average $191 \pm 4 \mathrm{~Kb}$ ), while the MpVs that can infect M. pusilla strain LAC38 carry genomes of $206 \pm 6 \mathrm{~Kb}$ on average, as estimated by PFGE. Full genome sequencing of several representatives from each group would conclusively determine whether the observed differences in genome sizes correspond to a deletion or insertion of one or several genes of ecological significance. It could also shed light on alternative propagation mechanisms as suggested by the differential characteristics we observed among the two MpV groups in this study.

Combined, the results in our study add to the known complexity of the $M$. pusilla-virus system (dsDNA and dsRNA $M$. pusilla virusess) by revealing a greater than previously thought diversity of dsDNA $M$. pusilla viruses, based overall on 500 phylogenetic distinction, average genome size, and the indications of the existence of enveloped and non-enveloped dsDNA $M$. pusilla viruses. In addition, the new chloroform-sensitive $\mathrm{MpV}$ isolates infectious to M. pusilla strain LAC38 suggest that different infection mechanisms may exist among dsDNA M. pusilla viruses. Our study also highlights the importance of basic characterization of cultured viruses to

505 reveal traits and key features that might not have been revealed by genome sequencing of a few isolates. Isolation and maintenance of host-virus systems in the laboratory provides extremely valuable resources for the investigation of major plankton-virus ecology questions, biogeochemical consequences of viral infection, microbial evolution and unveiling their potential for translational and applied science. 510 Often, thorough testing of hypotheses cannot be achieved by cultivation-independent 
approaches, in particular in the case of viruses, due to the lack of universal phylogenetic markers and the limitations in appropriate methods for in situ field measurements. Full benefit from these model systems can only be achieved through comprehensive knowledge of the virus characteristics.

\section{Acknowledgements}

We thank Anne-Claire Baudoux for her help with virus isolation, Anita Stoker, Bart Kay, Pim Steinberg, and Marco Flohil for their help in the laboratory and processing samples. TEM work was done at the Wageningen EM Center (WEMC), Wageningen University, The Netherlands. This work was part of the MICROVIR

520 project, which was supported by the division for Earth and Life Sciences Foundation (ALW), with financial aid from the Netherlands Organization for Scientific Research (NWO). 


\section{References}

Allen MJ, Martínez Martínez J, Schroeder DC, Somerfield PJ, Wilson WH (2007) Use of microarrays to assess viral diversity: from genotype to phenotype. Environ Microbiol 9:971-982

Baudoux A-C, Brussaard CPD (2005) Characterisation of different viruses infecting the marine harmful algal bloom species Phaeocystis globosa. Virology 341:80-90

540 Baudoux A-C, Noordeloos AAM, Veldhuis MJW, Brussaard CPD (2006) Virally induced mortality of Phaeocystis globosa during two spring blooms in temperate coastal waters. Aquat Microb Ecol 44:207-217

Bellec L, Clerissi C, Edern R, Foulon E, Simon N, Grimsley N, Desdevises Y (2014) Cophylogenetic interactions between marine viruses and eukaryotic picophytoplankton. BMC Evol Biol 14:59

Bellec L, Grimsley N, Moreau H, Desdevises Y (2009) Phylogenetic analysis of new Prasinoviruses (Phycodnaviridae) that infect the green unicellular algae Ostreococcus, Bathycoccus and Micromonas. Environ Microbiol Rep 1:114123

550 Bergh O, Borsheim KY, Bratbak G, Heldal M (1989) High abundance of viruses found in aquatic environments. Nature 340:467-468

Bratbak G, Egge JK, Heldal M (1993) Viral mortality of the marine alga Emiliania huxleyi (Haptophyceae) and termination of algal blooms. Mar Ecol Prog Ser 93:39-48

555 Brüssow H, Canchaya C, Hardt W-D (2004) Phages and the evolution of bacterial pathogens: from genomic rearrangements to lysogenic conversion. Microbiol Mol Biol Rev 68:560-602

Brussaard CPD (2004) Optimization of procedures for counting viruses by flow cytometry. Appl Environ Microbiol 70:1506-1513

560 Brussaard CPD, Kempers RS, Kop AJ, Riegman R, Heldal M (1996) Virus-like particles in a summer bloom of Emiliania huxleyi in the North Sea. Aquat Microb Ecol 10:105-113

Brussaard CPD, Noordeloos AAM, Sandaa RA, Heldal M, Bratbak G (2004) Discovery of a dsRNA virus infecting the marine photosynthetic protist

$565 \quad$ Micromonas pusilla. Virology 319:280-291

Chen F, Suttle CA (1995a) Amplification of DNA-polymerase gene fragments from viruses infecting microalgae. Appl Environ Microbiol 61:1274-1278

Chen F, Suttle CA (1995b) Nested Polymerase chain reaction with three highly degenerate primers for amplification and identification of DNA from related

$570 \quad$ organisms. Biotechniques 18:609 et seq.

Chen F, Suttle CA (1996) Evolutionary relationships among large double-stranded DNA viruses that infect microalgae and other organisms as inferred from DNA polymerase genes. Virology 219:170-178

Cottrell MT, Suttle CA (1991) Wide-spread occurrence and clonal variation in viruses which cause lysis of a cosmopolitan, eukaryotic marine phytoplankter, Micromonas pusilla. Mar Ecol Prog Ser 78:1-9

Cottrell MT, Suttle CA (1995) Genetic diversity of algal viruses which lyse the photosynthetic picoflagellate Micromonas pusilla (Prasinophyceae). Appl Environ Microbiol 61:3088-3091

580 Danovaro R, Dell'anno A, Trucco A, Serresi M, Vanucci S (2001) Determination of virus abundance in marine sediments. Appl Environ Microbiol 67:1384-1387 
Doceul V, Hollinshead M, van der Linden L, Smith GL (2010) Repulsion of superinfecting virions: a mechanism for rapid virus spread. Science 327:873876

585 Evans C, Archer SD, Jacquet S, Wilson WH (2003) Direct estimates of the contribution of viral lysis and microzooplankton grazing to the decline of a Micromonas spp. population. Aquat Microb Ecol 30:207-219

Guillard RRL (1975) Culture of phytoplankton for feeding marine invertebrates. In: Smith WL, Chanley MH (eds) Culture of marine invertebrate animals. Plenum Press, New York, p 29-60

Iyer L, Aravind L, Koonin E (2001) Common origin of four diverse families of large eukaryotic DNA viruses. J Virol 75:11720 - 11734

Lakeman MB, von Dassow P, Cattolico RA (2009) The strain concept in phytoplankton ecology. Harmful Algae 8:746-758

595 Law M, Carter GC, Roberts KL, Hollinshead M, Smith GL (2006) Ligand-induced and nonfusogenic dissolution of a viral membrane. Proc Natl Acad Sci U S A 103:5989-5994

Mackinder LCM, Worthy CA, Biggi G, Hall M, Ryan KP, Varsani A, Harper G, Wilson WH, Brownlee C, Schroeder DC (2009) A unicelular algal virus, Emiliania huxleyi virus 86, exploits an animal-like infection strategy. J Gen Virol 90:2306-2316

Manton I, Parke M (1960) Further observations on small green flagellates with special reference to possible relatives of Chromulina pusilla Butcher. J Mar Biol Assoc U.K. 39:275-298

605 Marie D, Brussaard CPD, Partensky F, Vaulot D (1999) Enumeration of phytoplankton, bacteria and viruses in marine samples. . In: Robinson J.P. ZD, P.N. Dean, A. Orfao and 4 others (ed) Current protocols in cytometry. John Wiley \& Sons, Chichester, p 11.11.11-11.11.15

610 Larsen A (2006) Variability in microbial population dynamics between similarly perturbed mesocosms. J Plankton Res 28:783-791

Martínez Martínez J, Schroeder DC, Wilson WH (2012) Dynamics and genotypic composition of Emiliania huxleyi and their co-occurring viruses during a coccolithophore bloom in the North Sea. FEMS Microbiol Ecol 81:315-323

615 Mayer JA, Taylor FJR (1979) A virus which lyses the marine nanoflagellate Micromonas pusilla. Nature 281

Moreau H, Piganeau G, Desdevises Y, Cooke R, Derelle E, Grimsley N (2010) Marine prasinovirus genomes show low evolutionary divergence and acquisition of protein metabolism genes by horizontal gene transfer. J Virol

$620 \quad 84: 12555-12563$

Mutsafi Y, Shimoni E, Shimon A, Minsky A (2013) Membrane assembly during the infection cycle of the giant Mimivirus. PLoS Pathog 9:e1003367

Nims RW, Plavsic M (2013) Intra-family and inter-family comparisons for viral susceptibility to heat inactivation. J Microb Biochem Tec 5:136-141

Not F, Latasa M, Marie D, Cariou T, Vaulot D, Simon N (2004) A single species, Micromonas pusilla (Prasinophyceae), dominates the eukaryotic picoplankton in the Western English Channel. Appl Environ Microbiol 70:4064-4072

Rohwer F, Vega-Thurber R (2009) Viruses manipulate the marine environment. Nature 459:207-212 
630 Sahlsten E (1998) Seasonal abundance in Skagerrak-Kattegat coastal waters and host specificity of viruses infecting the marine photosynthetic flagellate Micromonas pusilla. Aquat Microb Ecol 16:103-108

Schaum E, Rost B, Millar AJ, Collins S (2013) Variation in plastic responses of a globally distributed picoplankton species to ocean acidification. Nature Clim Change 3:298-302

Šlapeta J, López-García P, Moreira D (2006) Global dispersal and ancient cryptic species in the smallest marine eukaryotes. Mol Biol Evol 23:23-29

Smith GL, Vanderplasschen A, Law M (2002) The formation and function of extracellular enveloped vaccinia virus. J Gen Virol 83:2915-2931

640 Sym SD, Pienaar RN (1993) Further observations on Trichocystis, a subgenus of Pyramimonas (Prasinophyceae, Chlorophyta). Phycologia 32:338-350

Thingstad TF (2000) Elements of a theory for the mechanisms controlling abundance, diversity, and biogeochemical role of lytic bacterial viruses in aquatic systems. Limnol Oceanogr 45:1320-1328

645 van Etten JL, Graves MV, Muller DG, Boland W, Delaroque N (2002) Phycodnaviridae - large DNA algal viruses. Arch Virol 147:1479-1516

Waters RE, Chan AT (1982) Micromonas pusilla virus: the virus growth cycle and associated physiological events within the host cells; host range mutation. J Gen Virol 63:199-206

650 Wilhelm SW, Suttle CA (1999) Viruses and nutrient cycles in the sea. Viruses play critical roles in the structure and function of aquatic food webs. Bioscience 49:781-788

Wilson WH, Allen MJ (2009) Giant viruses and their genomes. In: Feng Z, Long M (eds) Viral genomes: Diversity, properties and parameters. Nova Science Publishers, Inc

Yutin N, Wolf Y, Raoult D, Koonin E (2009) Eukaryotic large nucleo-cytoplasmic DNA viruses: Clusters of orthologous genes and reconstruction of viral genome evolution. Virol J 6:223

Zingone A, Natale F, Biffali E, Borra M, Forlani G, Sarno D (2006) Diversity in morphology, infectivity, molecular characteristics and induced host resistance between two viruses infecting Micromonas pusilla. Aquat Microb Ecol 45:114

Zingone A, Sarno D, Forlani G (1999) Seasonal dynamics in the abundance of Micromonas pusilla (Prasinophyceae) and its viruses in the Gulf of Naples (Mediterranean Sea). J Plankton Res 21:2143-2159 
Figure 1. Representative transmission electron micrographs of thin sections of healthy and infected M. pusilla cells and free viruses.

(A) M. pusilla strain CCMP1545 uninfected; (B) M. pusilla strain CCMP1545 infected with MpV02T; (C) M. pusilla strain LAC38 uninfected; (D) M. pusilla strain

675 LAC38 infected with MpV03T; (E) free MpV06T particles from a M. pusilla strain LAC38 culture lysate. Arrows point at some MpVs within infected cells.

Figure 2. Phylogenetic tree based on DNA polymerase family B gene fragments.

Phylogenetic reconstruction was based on nucleotide sequences using Bayesian

680 Inference. Numbers indicate branch support as posterior probabilities. In bold are novel MpV isolates from this study, isolated with M. pusilla strain CCMP1545 ( $\mathbf{\Delta}$ ) or with M. pusilla strain LAC38 (•). In grey are MpV isolates from Cottrell and Suttle (1991), which were isolated with M. pusilla Plymouth 27 (from which CCMP1545 originated). Not highlighted are MpVs and other picoeukaryote viruses (OlV and 685 OtV, Ostreococcus spp.; BpV and BatV, Bathycoccus spp.) from Bellec et al. 2014. Letters A, B, and C within the names of these isolates indicate M. pusilla host clade. GenBank accession number for DNA polymerase sequences previously reported can be found within the respective references.

\section{Tables}

690 Table 1. Host strain specificity of 19 new MpV isolates from this study and MpVSP1 (Cottrell and Suttle 1991).

Clear boxes indicate no lysis; grey boxes indicate lysis; • denotes $\mathrm{MpV}$ from this host strain. Geographical origins: Pacif $=$ Pacific Ocean; Med = Mediterranean Sea; Sarg = 
Sargasso Sea; Sout $=$ Southern Ocean $;$ Nort $=$ North Sea $;$ Engl = English Channel;

Balt $=$ Baltic Sea $;$ Duct $=$ Dutch Coastal waters.

Table 2. M. pusilla-virus isolates data including genome size as estimated in this study and GenBank accession number for their partial DNA polymerase B sequences.

Table 3. Sensitivity of $\mathrm{MpV}$ isolates to exposure to a wide range of temperature and to chloroform.

Grey boxes indicate lysis by the $\mathrm{MpV}$ isolate after the specified treatment. Clear boxes indicate loss of viral infectivity.

\section{Supplementary Information}

Supplementary Figure S1. Representative flow cytometry plot showing virus 705 and bacteria populations.

(A) M. pusilla strain CCMP1545 infected with MpV40T; (B) M. pusilla strain CCMP1545 uninfected. Discrimination of groups was based on green fluorescence and side scatter signatures.

\section{Supplementary Figure S2. PFGE photographs.}

710 The $\mathrm{MpV}$ isolate loaded into each well is indicated at the top of the lane. $\lambda$ symbols indicate wells loaded with DNA Lambda ladder plugs. Variable amounts of each $\mathrm{MpV}$ isolate were randomly loaded onto different gels to increase confidence when estimating genome size across samples that were electrophoresed separately. The arrows mark the $\sim 200 \mathrm{~Kb}$ bands identified as $\mathrm{MpV}$ genomes. Bands $<48.5 \mathrm{~Kb}$ are

715 likely from phages present in some of the cultures. Non-MpV denotes wells that were loaded with samples other than $\mathrm{MpV}$ isolates and were not relevant for this study. 


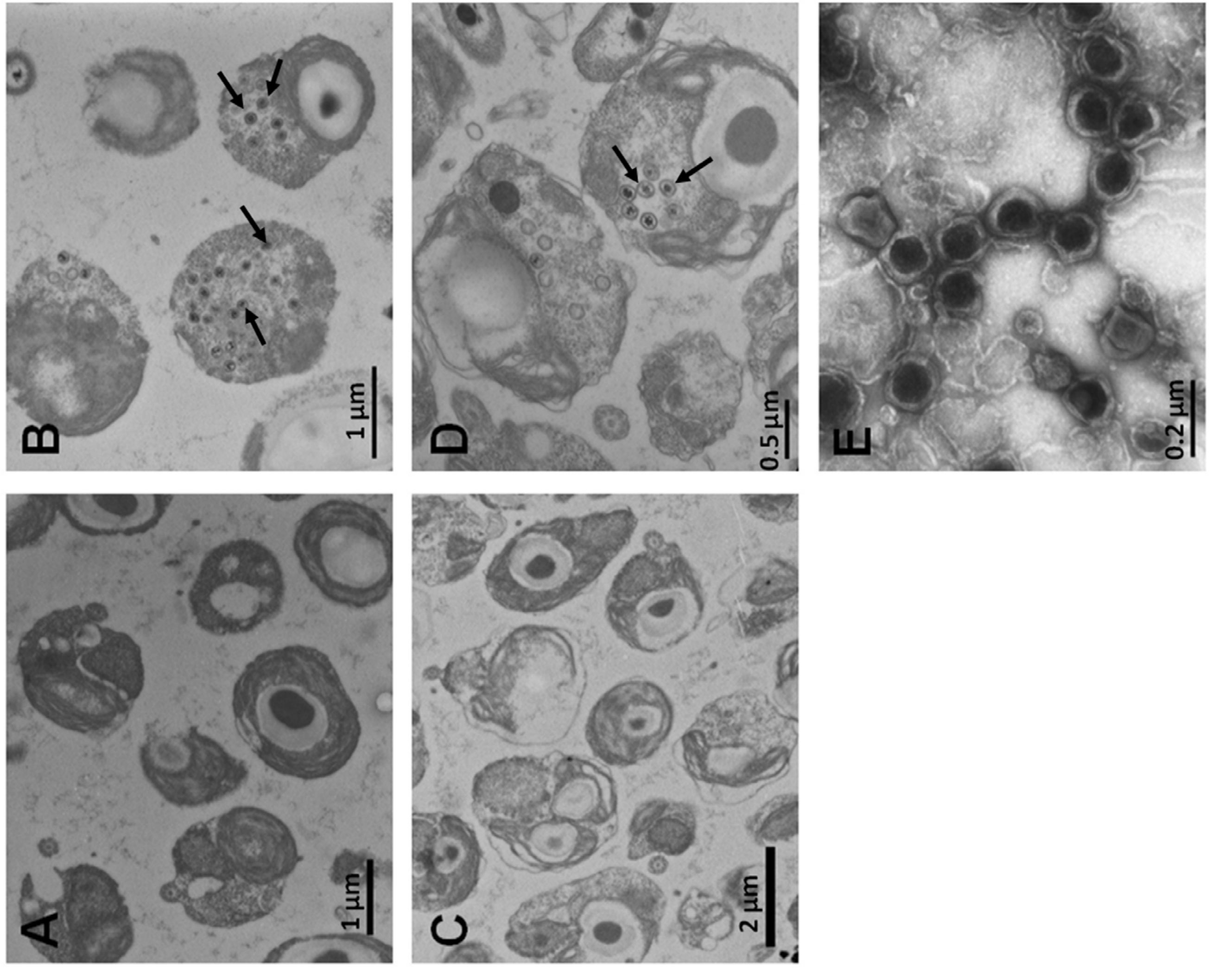




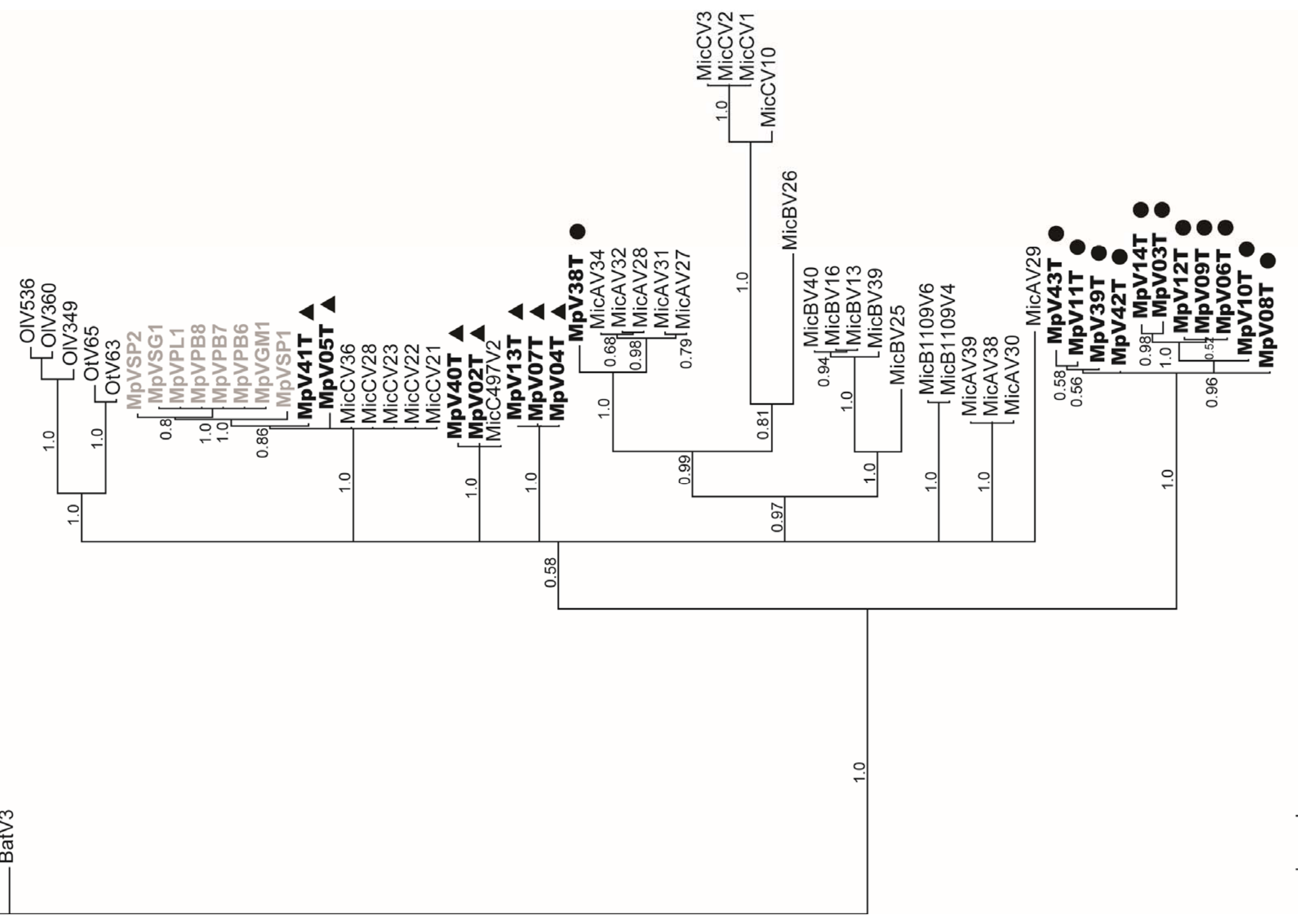


Table 1. Host strain specificity of 19 new MpV isolates from this study and MpVSP1 (Cottrell and Suttle 1991). Micromonas pusilla-viruses (MpVs)

\begin{tabular}{|c|c|c|c|c|c|c|c|c|c|c|c|c|c|c|c|c|c|c|c|c|c|c|c|}
\hline \multirow{2}{*}{\multicolumn{2}{|c|}{$\begin{array}{c}\text { Host } \\
\text { Clade } \\
\end{array}$}} & \multirow[t]{2}{*}{ Origin } & \multirow[b]{2}{*}{ Strain } & \multirow{2}{*}{$\frac{\text { Nor }}{\mathbf{0 2 T}}$} & \multirow{2}{*}{$\begin{array}{l}\text { Nor } \\
\text { 04T } \\
\end{array}$} & \multirow{2}{*}{$\begin{array}{l}\text { Nor } \\
\mathbf{0 5 T} \\
\end{array}$} & \multirow{2}{*}{$\begin{array}{l}\text { Nor } \\
\text { 07T } \\
\end{array}$} & \multirow{2}{*}{$\begin{array}{l}\text { Nor } \\
13 \mathrm{~T} \\
\end{array}$} & \multirow{2}{*}{$\frac{\text { Pac }}{\text { SP1 }}$} & \multirow{2}{*}{$\frac{\text { Eng }}{40 \mathrm{~T}}$} & \multirow{2}{*}{$\frac{\text { Eng }}{\mathbf{4 1 T}}$} & \multirow{2}{*}{$\begin{array}{l}\text { Nor } \\
\mathbf{0 3 T}\end{array}$} & \multirow{2}{*}{$\begin{array}{l}\text { Nor } \\
\text { 06T } \\
\end{array}$} & \multirow{2}{*}{$\begin{array}{l}\text { Nor } \\
\mathbf{0 8 T}\end{array}$} & \multirow{2}{*}{$\frac{\text { Dut }}{\text { 09T }}$} & \multirow{2}{*}{$\frac{\text { Dut }}{\text { 10T }}$} & \multirow{2}{*}{$\frac{\text { Dut }}{11 \mathrm{~T}}$} & \multirow{2}{*}{$\frac{\text { Dut }}{12 \mathrm{~T}}$} & \multirow{2}{*}{$\frac{\text { Nor }}{14 \mathrm{~T}}$} & \multirow{2}{*}{$\frac{\text { Med }}{38 \mathrm{~T}}$} & \multirow{2}{*}{$\begin{array}{l}\text { Med } \\
39 T\end{array}$} & \multirow{2}{*}{$\begin{array}{l}\text { Eng } \\
\mathbf{4 2 T} \\
\end{array}$} & \multirow{2}{*}{$\frac{\text { Eng }}{43 T}$} \\
\hline & & & & & & & & & & & & & & & & & & & & & & & \\
\hline \multirow{17}{*}{ 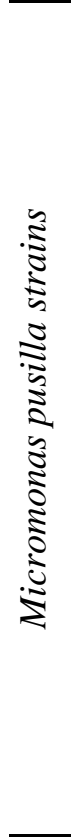 } & A & $\mathrm{Pac}$ & RCC299 & & & & & & & & & & & & & & & & & & & & \\
\hline & A & Med & RCC449 & & & & & & & & & & & & & & & & & & & & \\
\hline & A & Sar & RCC450 & & & & & & & & & & & & & & & & & & & & \\
\hline & A & Sou & RCC658 & & & & & & & & & & & & & & & & & & & & \\
\hline & A & Med & RCC372 & & & & & & & & & & & & & & & & & & & & \\
\hline & A & Nor & RCC692 & & & & & & & & & & & & & & & & & & & & \\
\hline & $?$ & Sou & RCC803 & & & & & & & & & & & & & & & & & & & & \\
\hline & B & Med & RCC434 & & & & & & & & & & & & & & & & & & & & \\
\hline & B & Eng & RCC418 & & & & & & & & & & & & & & & & & & & & \\
\hline & B & Eng & RCC461 & & & & & & & & & & & & & & & & & & & & \\
\hline & $\mathrm{C}$ & Med & RCC498 & & & & & & & & & & & & & & & & & & & & \\
\hline & $\mathrm{C}$ & Eng & RCC465 & & & & & & & & & & & & & & & & & & & & \\
\hline & $\mathrm{C}$ & Eng & RCC834 & & & & & & & & & & & & & & & & & & & & \\
\hline & $\mathrm{C}$ & Nor & RCC629 & & & & & & & & & & & & & & & & & & & & \\
\hline & $\mathrm{C}$ & Bal & RCC373 & & & & & & & & & & & & & & & & & & & & \\
\hline & $\mathrm{C}$ & Eng & CCMP1545 & $\bullet$ & $\bullet$ & $\bullet$ & - & $\bullet$ & - & $\bullet$ & - & & & & & & & & & & & & \\
\hline & A & Bal & LAC38 & & & & & & & & & - & - & - & - & - & - & - & - & - & - & - & - \\
\hline
\end{tabular}

Clear boxes indicate no lysis; grey boxes indicate lysis; $\bullet$ denotes $\mathrm{MpV}$ from this host strain. Geographical origins: Pac $=$ Pacific Ocean; Med = Mediterranean Sea; Sar $=$ Sargasso Sea; Sou $=$ Southern Ocean $;$ Nor $=$ North Sea; Eng $=$ English Channel; Bal $=$ Baltic Sea; Dut $=$ Dutch Coastal waters . 
Table 2. M. pusilla-virus isolates' data including genome size as estimated in this study and GenBank accession number for their partial DNA polymerase B sequences.

\begin{tabular}{|c|c|c|c|c|c|}
\hline $\begin{array}{l}\text { MpV } \\
\text { strain }\end{array}$ & Geographical origin & Isolation date & $\begin{array}{l}\text { Isolation } \\
\text { host }\end{array}$ & $\begin{array}{c}\text { Genome } \\
\text { size } \\
\text { (Kbp) }\end{array}$ & $\begin{array}{l}\text { GenBank } \\
\text { Accession \# }\end{array}$ \\
\hline $02 \mathrm{~T}$ & North Sea 54 29'N; 04 38'E & July 2003 & \multirow{8}{*}{$\begin{array}{l}\text { M. pusilla } \\
\text { CCMP1545 }\end{array}$} & 195 & KJ955609 \\
\hline $04 \mathrm{~T}$ & North Sea 59 34'N; 00 30'E & July 2003 & & 194 & KJ955611 \\
\hline $05 T$ & North Sea 57 83'N; 07 42'E & July 2003 & & 189 & KJ955612 \\
\hline 07T & North Sea 56 43'N; $0600^{\prime} \mathrm{E}$ & July 2003 & & 186 & KJ955614 \\
\hline $13 T$ & North Sea $5900^{\prime} \mathrm{N} ; 0000^{\prime} \mathrm{E}$ & July 2003 & & 187 & KJ955620 \\
\hline $40 \mathrm{~T}$ & English Channel 48 45'N; 03 57'W & April 2006 & & 194 & KJ955624 \\
\hline $41 \mathrm{~T}$ & English Channel 48 45'N; 03 57'W & April 2006 & & 194 & KJ955625 \\
\hline SP1 & Pacific Ocean 27 50'N; 97 04'W & October 1990 & & 186 & U32975* \\
\hline 03T & North Sea 55 46'N; 02 56'E & July 2003 & \multirow{12}{*}{$\begin{array}{l}\text { M. pusilla } \\
\text { LAC38 }\end{array}$} & 212 & KJ955610 \\
\hline $06 \mathrm{~T}$ & North Sea 57 83'N; 07 42'E & July 2003 & & 200 & KJ955613 \\
\hline $08 \mathrm{~T}$ & North Sea $5643^{\prime} \mathrm{N} ; 06$ 00'E & July 2003 & & 208 & KJ955615 \\
\hline 09T & Dutch Coast 52 10'N; 04 16'E & April 2003 & & 204 & KJ955616 \\
\hline $10 \mathrm{~T}$ & Dutch Coast 52 10'N; 04 16'E & April 2003 & & 210 & KJ955617 \\
\hline $11 \mathrm{~T}$ & Dutch Coast 52 10'N; 04 16'E & April 2003 & & 203 & KJ955618 \\
\hline $12 \mathrm{~T}$ & Dutch Coast 52 10'N; 04 16'E & May 2003 & & 200 & KJ955619 \\
\hline $14 \mathrm{~T}$ & North Sea 54 29'N; 04 38'E & July 2003 & & 209 & KJ955621 \\
\hline $38 \mathrm{~T}$ & Mediterranean Sea 41 40'N; 02 48'W & March 2006 & & 205 & KJ955622 \\
\hline $39 T$ & Mediterranean Sea 41 40'N; 02 48'W & March 2006 & & 207 & KJ955623 \\
\hline $42 \mathrm{~T}$ & English Channel 48 45'N; 03 57'W & April 2006 & & 204 & KJ955626 \\
\hline $43 \mathrm{~T}$ & English Channel 48 45'N; 03 57'W & April 2006 & & 205 & KJ955627 \\
\hline
\end{tabular}

* Chen and Suttle 1996 
Table 3. Sensitivity of $\mathrm{MpV}$ isolates to exposure to a wide range of temperatures and to chloroform.

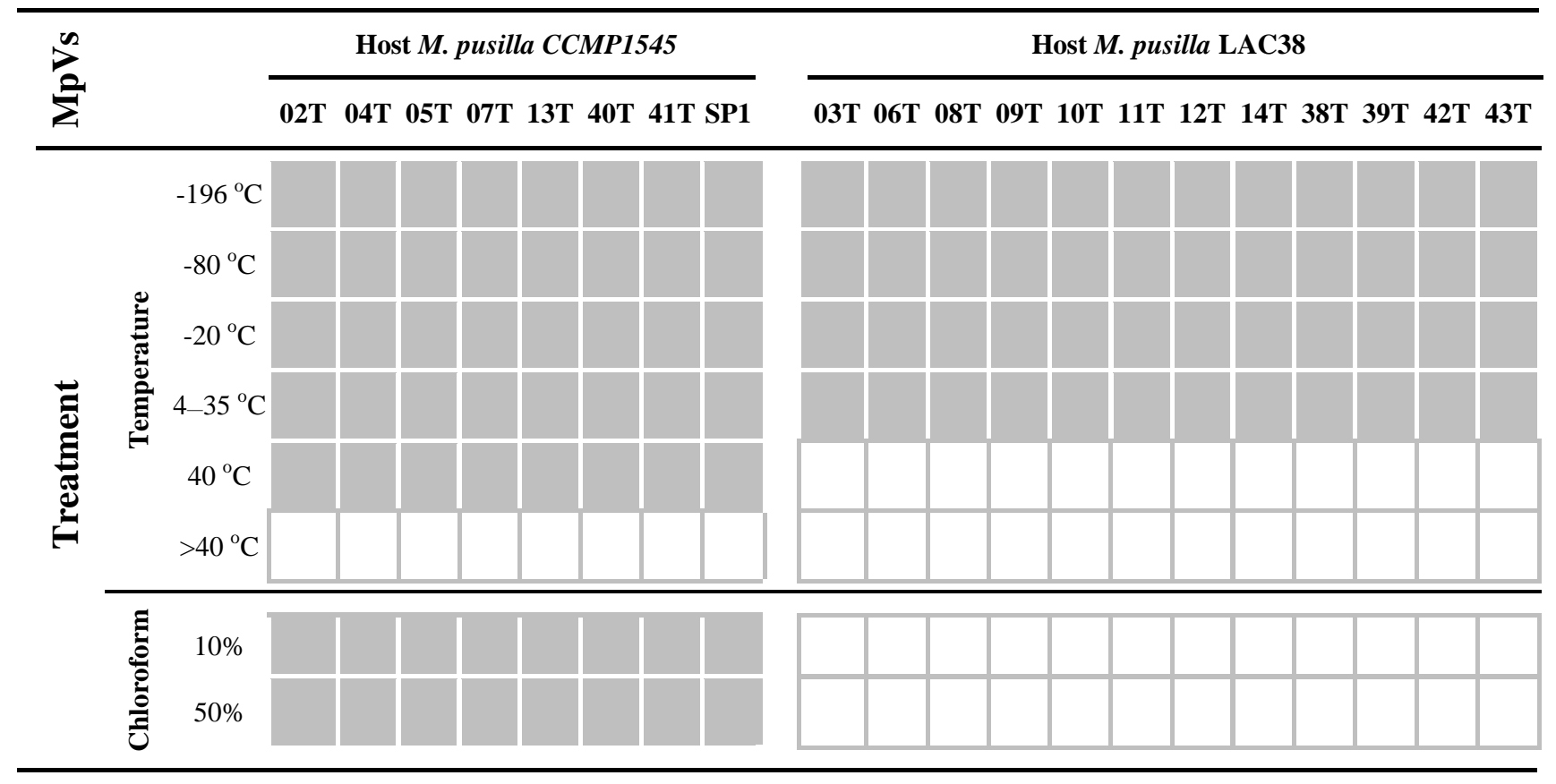

Clear boxes indicate loss of infectivity. Grey boxes indicate that the $\mathrm{MpV}$ isolate caused lysis of the host after the specified treatment. 


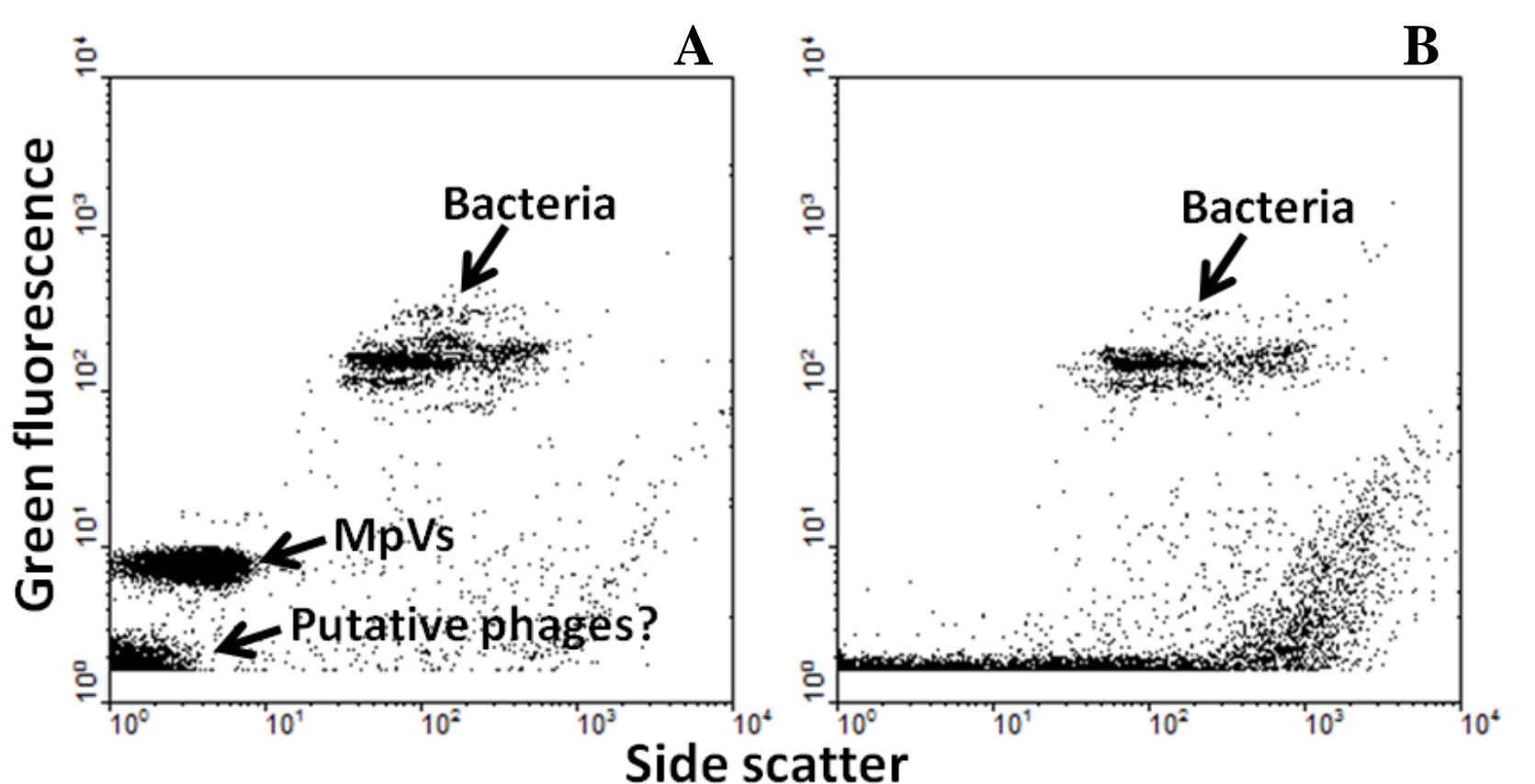

Supplementary Figure S1. Representative flow cytometry plots showing virus and bacteria populations.

(A) M. pusilla strain CCMP1545 infected with MpV40T; (B) M. pusilla strain CCMP1545

uninfected. Plots from uninfected cultures in late stationary phase (example given) and in exponential phase look the same. Discrimination of groups was based on green fluorescence and side scatter signatures. 


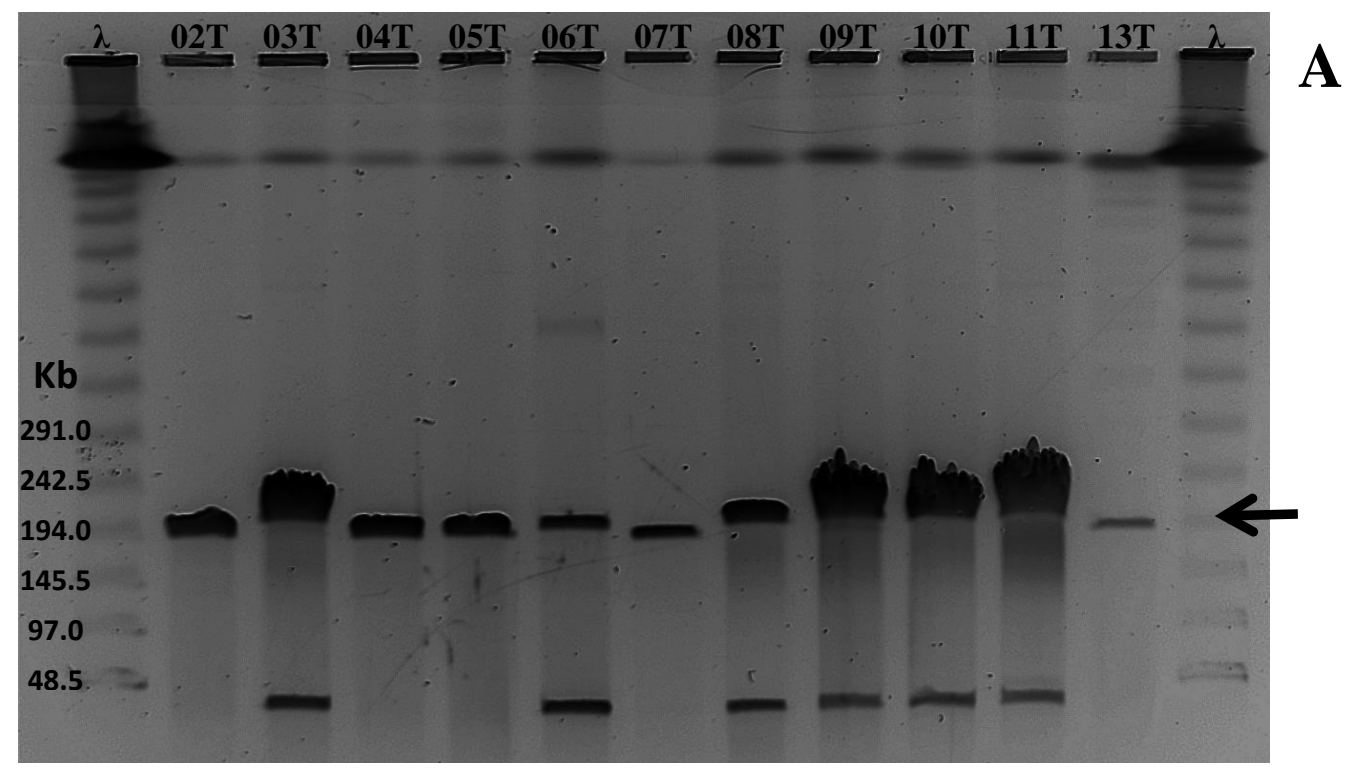

Filename: PFGE $2 \mathrm{~h} 1 \mathrm{~min}$ d 10-3-06

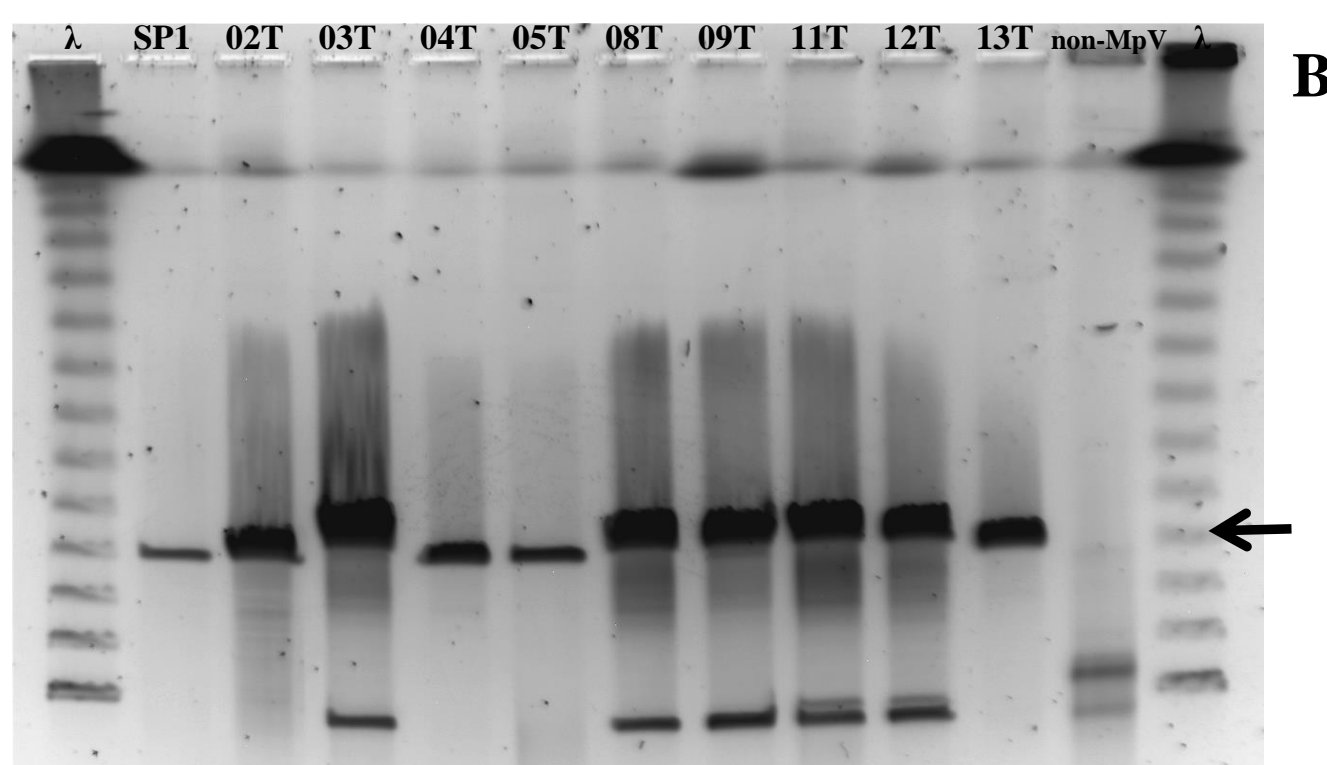

Filename: PFGE 1.5h 1min 30-3-06

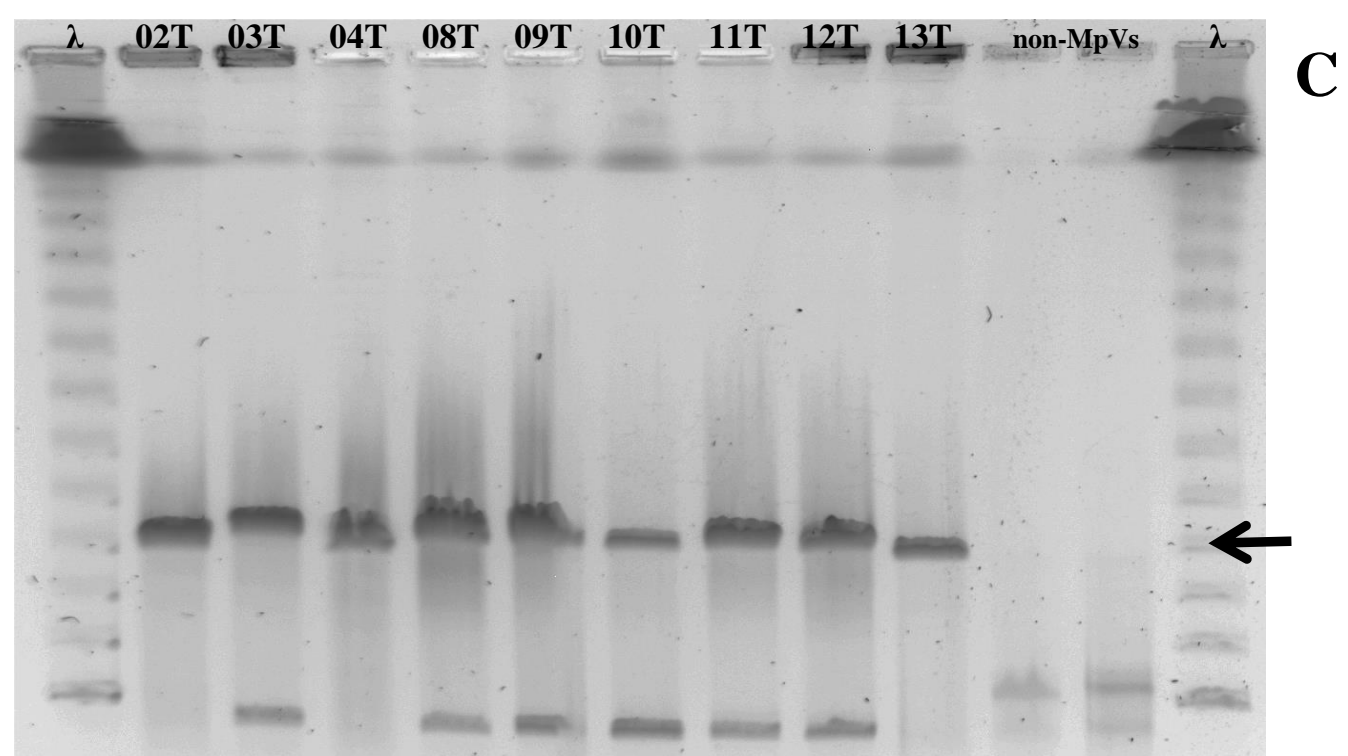

Filename: PFGE A 30min 15sec 6-4-06 


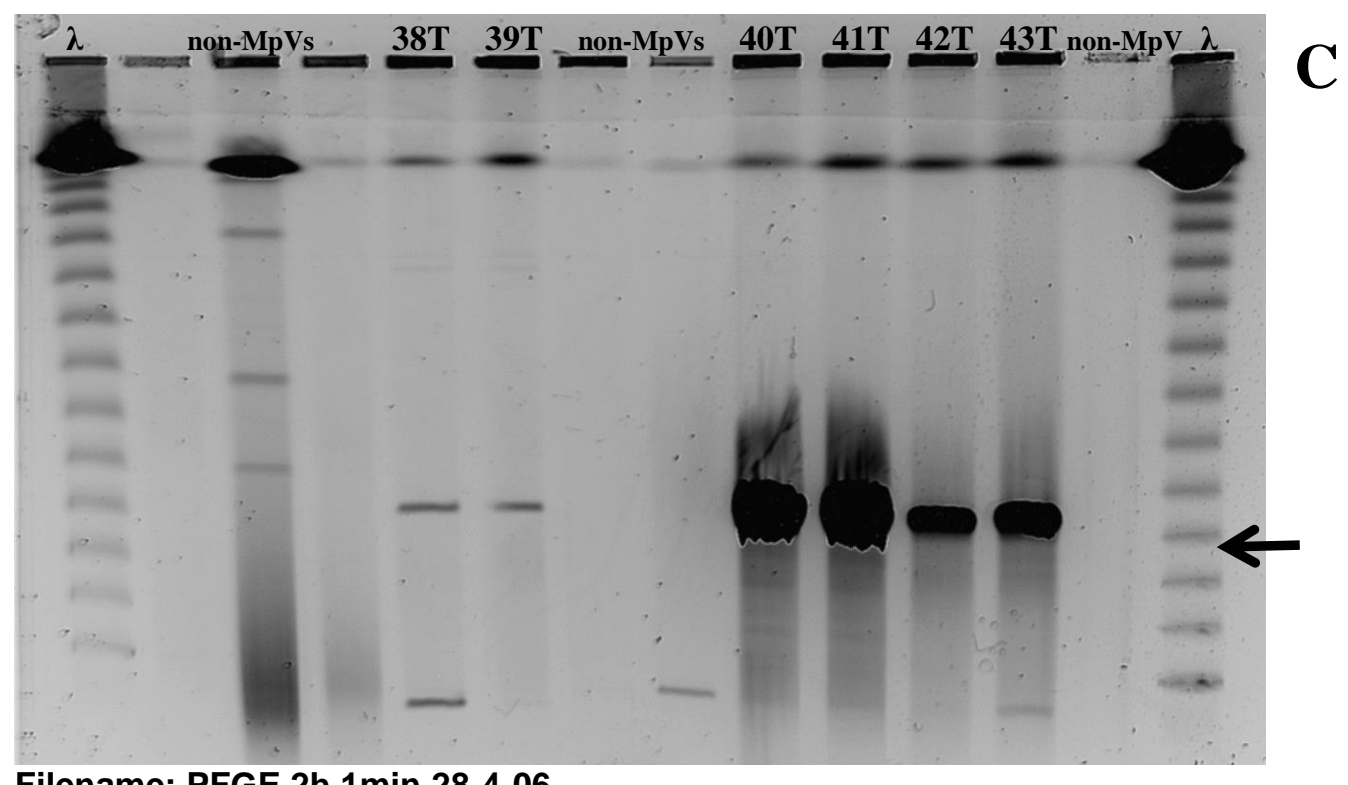

Filename: PFGE 2h 1min 28-4-06

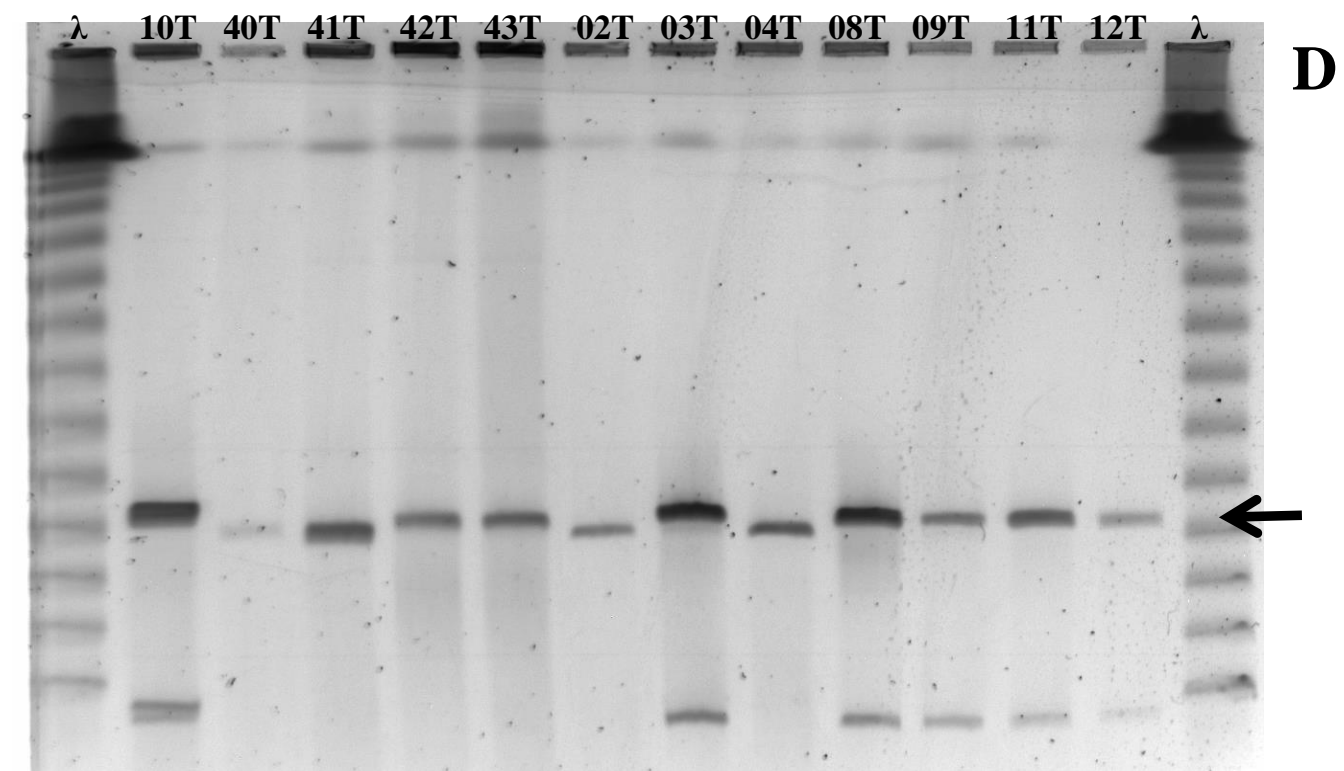

Filename: PFGE 35min 1.30min 19-5-06

\section{Supplementary Figure S2. PFGE photographs.}

The $\mathrm{MpV}$ isolate loaded into each well is indicated at the top of the lane. $\boldsymbol{\lambda}$ symbols indicate wells loaded with DNA Lambda ladder plugs. Variable amounts of each $\mathrm{MpV}$ isolate were randomly loaded onto different gels to increase confidence when estimating genome size across samples that were electrophoresed separately. The arrows mark the $\sim 200 \mathrm{~Kb}$ bands identified as $\mathrm{MpV}$ genomes. Bands $<48.5 \mathrm{~Kb}$ are likely from phages present in some of the cultures. Non-MpV denotes wells that were loaded with samples other than $\mathrm{MpV}$ isolates and were not relevant for this study. 